1. United States Department of Commerce Technology Administration National Institute of Standards and Technology

NISTIR 5080

\title{
Ultrasonic Measurement of Stress in Pin and Hanger Connections
}
A.V. Clark
D. Gallagher
C.S. Hehman
P.A. Fuchs
M.G. Lozev 



\section{Ultrasonic Measurement of Stress in Pin and Hanger Connections}
A.V. Clark
D. Gallagher
C.S. Hehman
P.A. Fuchs
M.G. Lozev

Materials Reliability Division Materials Science and Engineering Laboratory National Institute of Standards and Technology

Boulder, Colorado 80303-3328

January 1999

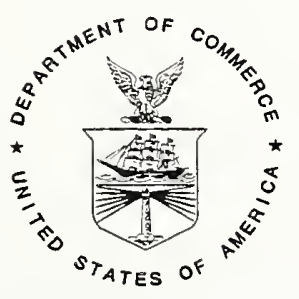

U.S. DEPARTMENT OF COMMERCE, William M. Daley, Secretary 


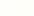




\section{CONTENTS}

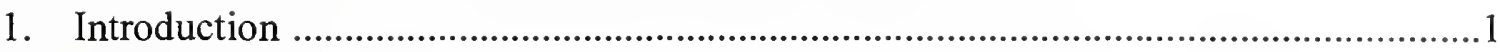

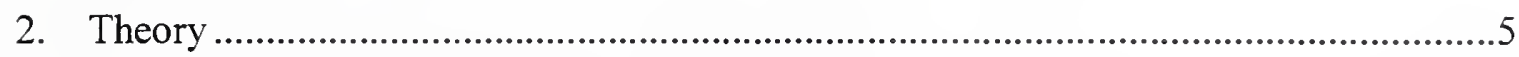

2.1 Stresses in Pin and Hanger Connections ..............................................................5

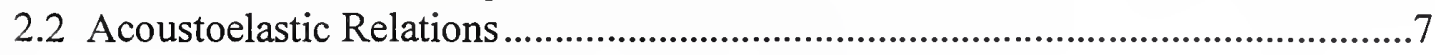

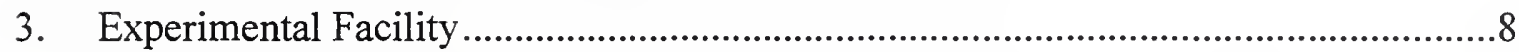

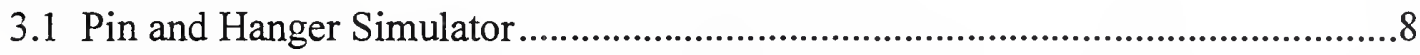

3.2 Ultrasonic Equipment ....................................................................................... 10

3.3 Electromagnetic-Acoustic Transducer ................................................................12

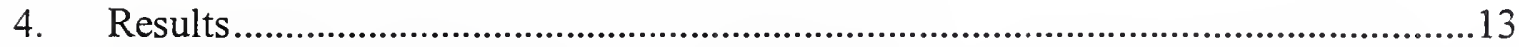

4.1 Description of Stress Measurement Scenarios..............................................13

4.2 Continuous Monitoring .................................................................................14

4.3 Intermittent Monitoring .....................................................................................14

4.4 Measurement of Hanger Stress with No A Priori Information ...........................17

4.5 Effect of Measurement Uncertainties ..............................................................19

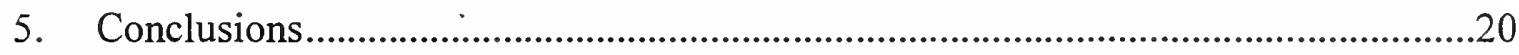

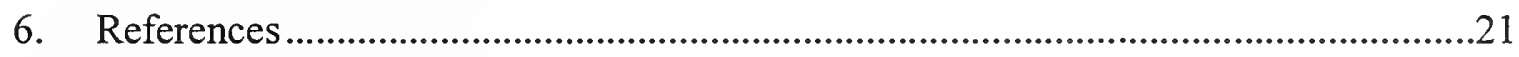

APPENDIX 


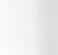




\title{
Ultrasonic Measurement of Stress \\ in Pin and Hanger Connections
}

\author{
A.V. Clark \\ D. Gallagher \\ C.S. Hehman \\ National Institute of Standards and Technology \\ Boulder, Colorado 80303 \\ P.A. Fuchs \\ Federal Highway Administration \\ McLean, Virginia 22101 \\ M.G. Lozev \\ Virginia Transportation Research Council \\ Charlottesville, Virginia 22903
}

\begin{abstract}
Pin and hanger connections are used in bridges to suspend an interior span from the outer spans. The connections can sometimes lock up due to corrosion. If lockup occurs the stresses in the connection are cycled due to thermal expansion and contraction of the bridge; fatigue cracking and failure may occur. We constructed an apparatus to simulate a locked-up pin and hanger connection. We performed proof of concept tests of a method to detect stresses in pin and hanger connections. The method uses the stress-induced changes in sound velocity of shear waves polarized parallel and perpendicular to the hanger axis. The birefringence is the normalized difference in these shear wave velocities. We measured the birefringence at opposite sides of the hangers, at midsection. We simulated three scenarios: continuous monitoring of hanger status; intermittent monitoring from a known initial state; measurement with no a priori knowledge of hanger status. Good agreement with strain gauge data was obtained for all three scenarios.
\end{abstract}

Key words: bridges, connections, EMATs, stress, ultrasonics

\section{Introduction}

Pin and hanger connections are sometimes used in bridge construction to suspend interior spans. In the simplest version one span is suspended from outer spans which are cantilevered over supporting piers. A closeup of a typical pin and hanger connection is shown in Figure 1. Here we show a hanger on one side of the girders; there will be an identical hanger on the opposite side. 


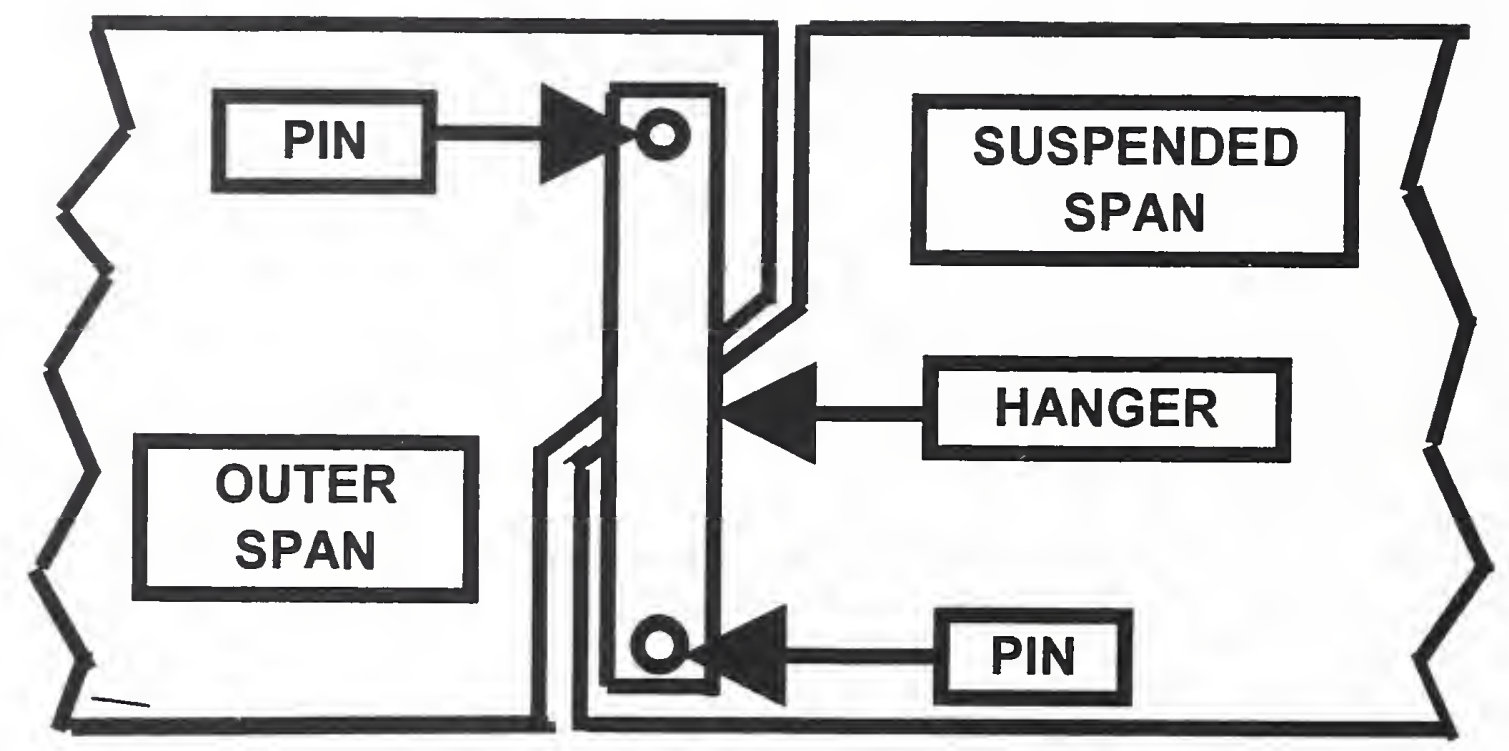

Figure 1. View of typical pin and hanger connection from outside of bridge.

Since the connections accommodate thermal expansion and contraction of the bridge they are located at expansion joints. Consequently, road de-icing salts can wash down into the pin holes. As corrosion products swell, they reduce clearance in pin holes and may cause lockup [1]. As the bridge expands and contracts the pin will be in torsion and the hanger in bending. Then fatigue cracks can initiate in locked-up pins and hangers with possible failure of the connection.

Visual inspection is often used to characterize the status of these connections but can determine only if corrosion exists (a necessary but not sufficient condition for lockup). Furthermore, corrosion may not always be visible.

Ultrasonics can be used to determine if the pins have developed cracks [2]. This method is made complicated by pin geometries, which can have wear grooves, etc. Furthermore, the absence of cracks does not necessarily indicate a safe connection; fatigue cracks may be so small as to be undetectable. Therefore, we seek a method that is simpler than imaging pins for cracks and can detect connection distress before cracking.

Ultrasonics can also be used to measure stress in the hangers, since stress causes change in sound speed. This method has recently been used, for example, to determine stresses in cast steel railroad wheels of U.S. manufacture. Here orthogonally polarized shear waves were propagated through the rims of wheels which had residual stress induced by induction heating [3] and drag braking on a dynamometer [4]. A good correlation between ultrasonic stress measurement and a destructive measure of wheel residual stress was found. Similar results have been reported on wheels manufactured outside the U.S. [5-7]. 
This technique has also been evaluated in field tests on two bridges [8]. In the first test, the residual stress in a girder in a simply supported span was measured. In the second, ultrasonic measurements were made at opposite sides of a bridge that has no expansion joints. The bridge had been previously instrumented to monitor its status. Strain gage readings at one side indicated compressive stresses. These were large enough to raise concerns about possible buckling and plastic deformation of the girders. The ultrasonic data indicated safe operation; this was verified by subsequent replacement of suspect strain gage instrumentation.

The authors of Ref. 9 measured the time-of-flight of orthogonally polarized shear waves traveling through the hanger thickness. The normalized difference in time of flight (the acoustic birefringence $\mathrm{B}$ ) is related to the stress in the hanger:

$$
\mathrm{B}=\mathrm{B}_{\mathrm{o}}-\mathrm{m} \sigma_{\mathrm{xx}},
$$

where $\sigma_{\mathrm{xx}}$ is the stress acting along the hanger axis and $\mathrm{m}=$ the stress-acoustic constant (units of $\mathrm{MPa}^{-1}$ ).

Note the presence of the additional term $B_{0}$ in eq (1). The hangers are typically made of rolled steel. The rolling process creates a preferential orientation of the grains (texture) in the hanger. The shear moduli in the rolling and transverse directions will be slightly different. Hence even in the absence of stress the velocities of shear waves polarized in these directions will differ. To determine the stress it is necessary to account for the contribution of $B_{0}$.

To deal with the problem of determination of $B_{o}$ the authors of Ref. 9 used the following procedure. A scale model replica of the bridge hanger was constructed and tested in uniaxial tension. Measurements were made at five locations on the hanger: four around one of the pins, and one at the center. The assumption was made that the ratios of stresses at these locations in the bridge hanger and model hanger are the same. It was concluded that while the procedure "resulted in stress values that appear reasonable, it has not been confirmed that this procedure is generally valid" [9].

One obvious problem with this approach is that it requires construction and testing of a scale model for each pin and hanger geometry. Since there is no universal design, the procedure requires a separate test for each different connection. Furthermore the results pertain only to uniaxial tension tests. No procedure is given to determine whether the hanger is distressed (when it will be in bending).

We present here an alternative means to use the birefringence technique to characterize the status of pin and hanger connections. Our method requires no scale- 
model testing. Rather, we make birefringence measurements at opposite sides of the hanger, at the same elevation. From eq (1) we have

$$
B^{1}-B^{r}=m\left(\sigma_{x x}{ }^{r}-\sigma_{x x}{ }^{1}\right),
$$

where " 1 " and " $\mathrm{r}$ " denote readings on the left and right sides of the hanger.

In normal operation, the hanger carries only uniaxial stress (at some distance from the pin hole). Therefore, for good hangers the difference in birefringence measurements vanishes. Conversely, a defective connection will have a bending stress in the hanger. This will be is antisymmetric about the vertical centerline of the hanger, so the right side of eq (2) will not vanish. Therefore a difference in birefringence measurements indicates a distressed connection.

In actuality the texture induced anisotropy $\mathrm{B}_{\mathrm{o}}$ is not constant, but varies slightly due to inhomogeneity in material processing. Hence, when we subtract $B^{1}-B^{r}$, we will have an uncertainty in stress characterized by $\delta \mathrm{B}_{0} / \mathrm{m}$ where $\delta \mathrm{B}_{0}$ is the standard deviation of the $B_{0}$ values in the hanger.

This uncertainty poses a challenge for our method. The desired result (for good connections) is to have $\mathrm{B}^{1}-\mathrm{B}^{\mathrm{r}}=0$ but we have the possibility of a "false reject." That is, we may classify connections as bad when in fact they are good. In practice this could lead to unnecessary and costly repairs since the span has to be jacked up to take the pin out. We will return to this point later.

As a first step in proving our technique, we designed and constructed a pin and hanger simulation facility. Two hangers were mounted on a 12-tooth spline which locked up one end of the hangers (no rotation allowed). A "free" pin connected the other ends of the hangers. This pin is loaded by the piston of our mechanical testing machine to generate bending in the hanger and torsion in the spline. We mounted strain gages at various locations on the hangers to determine the stress state.

Then we performed ultrasonic measurements of acoustic birefringence. We made measurements to simulate several scenarios: (1) continuous monitoring, (2) intermittent monitoring of stress change from a known initial state, (3) determination of stress with no a priori information.

In scenario 1, we left the transducer in situ, measured changes in birefringence for changing load, converted to equivalent changes in strain and compared with strain gage results.

In scenario 2, we performed initial birefringence measurements at 1 and $\mathrm{r}$ locations and removed the transducer. We then changed the load, measured the new birefringence, and determined the equivalent strain change. We repeated the sequence for several 
different loads. This models a case of initial characterization at the time of installation of a new hanger; we then return to the bridge to measure changes from this initial state.

In scenarios 1 and 2 we suppress variability in $B_{0}$, since we measure $B_{0}$ at each 1 and $r$ location as initial values. In scenario 3 we know nothing about the initial status and our values of $B^{1}-B^{r}$ have uncertainty due to variability in $B_{0}$. Scenario 3 is the most likely application for our method since hangers are already installed. However, scenarios 1 and 2 are also useful since they help characterize any other measurement errors (other than uncertainty in $B_{0}$ ).

As expected, we found the best agreement between ultrasonic and strain gage results for scenario 1 and the poorest for scenario 3. However, even for scenario 3 the results were encouraging, so we have demonstrated proof of concept in a laboratory setting.

\section{Theory}

\subsection{Stresses in Pin and Hanger Connections}

In normal operation the pins rotate freely to accommodate thermal expansion. At some distance from the stress concentrations near the pins, the hangers are in uniaxial tension. The stress $\sigma_{x x}$ is related to the deadload W carried by the hanger: $\sigma_{x x}=W / A$, where $\mathrm{A}$ is the hanger cross-sectional area.

Now suppose, for example, that the top pin locks up. Then we have a horizontal force $\mathrm{P}$ acting on both pins and a torque $\tau$ acting on the "frozen" pin; see Figure 2. From moment equilibrium $\tau=\mathrm{PL}$, where $\mathrm{L}$ is the distance between pins.

At any hanger cross section at a vertical distance $\mathrm{X}$ from the free pin, there is a bending moment, $\mathrm{M}=\mathrm{PX}$. The bending moment causes an additional normal stress $\sigma_{\mathrm{x} \times}$ acting along the hanger axis. The integral of $\sigma_{x x, b} Y$ over the cross-sectional area equals $\mathrm{M}$, where $\mathrm{Y}=$ distance from the centerline of the hanger. Likewise $\mathrm{P}$ gives rise to shear stress $\sigma_{x y}$; the integral of $\sigma_{\mathrm{xy}}$ over the cross section equals $\mathrm{P}$.

In the pin the torque $\tau$ causes shear stress $\sigma_{\theta z}$ ( $\mathrm{z}$ is oriented along the pin axis). The integral of $r \sigma_{\theta z}$ over the pin cross-sectional area equals $\tau$, with $r=$ radial distance from pin center.

For experimental design, we use simple beam theory to estimate the stresses at some distance away from the pins. We idealize the hanger as a tip loaded cantilever beam. The bending stress for this case is

$$
\sigma_{\mathrm{xx}, \mathrm{b}}=\mathrm{PXY} / \mathrm{I},
$$


where I is the area moment of inertia of the hanger. A typical hanger has rectangular cross section, so $I=b^{3} / 12$, where $b=$ thickness, $h=$ width. The shear stress is given by

$$
\sigma_{x y}=P\left(h^{2} / 4-Y^{2}\right) / 2 I .
$$

Note that $\sigma_{\mathrm{xy}}=0$ at the edge of the hanger and reaches a maximum at the centerline; the bending stress $\sigma_{x x \times b}=0$ on the centerline and reaches its extreme values at the edges (tensile on one side and compressive on the other). The ratio of the maximum $\sigma_{\mathrm{xx}, b}$ to maximum $\sigma_{\mathrm{xy}}$ is $4 \mathrm{X} / \mathrm{h}$. Hence for long slender hangers the bending stress is dominant.

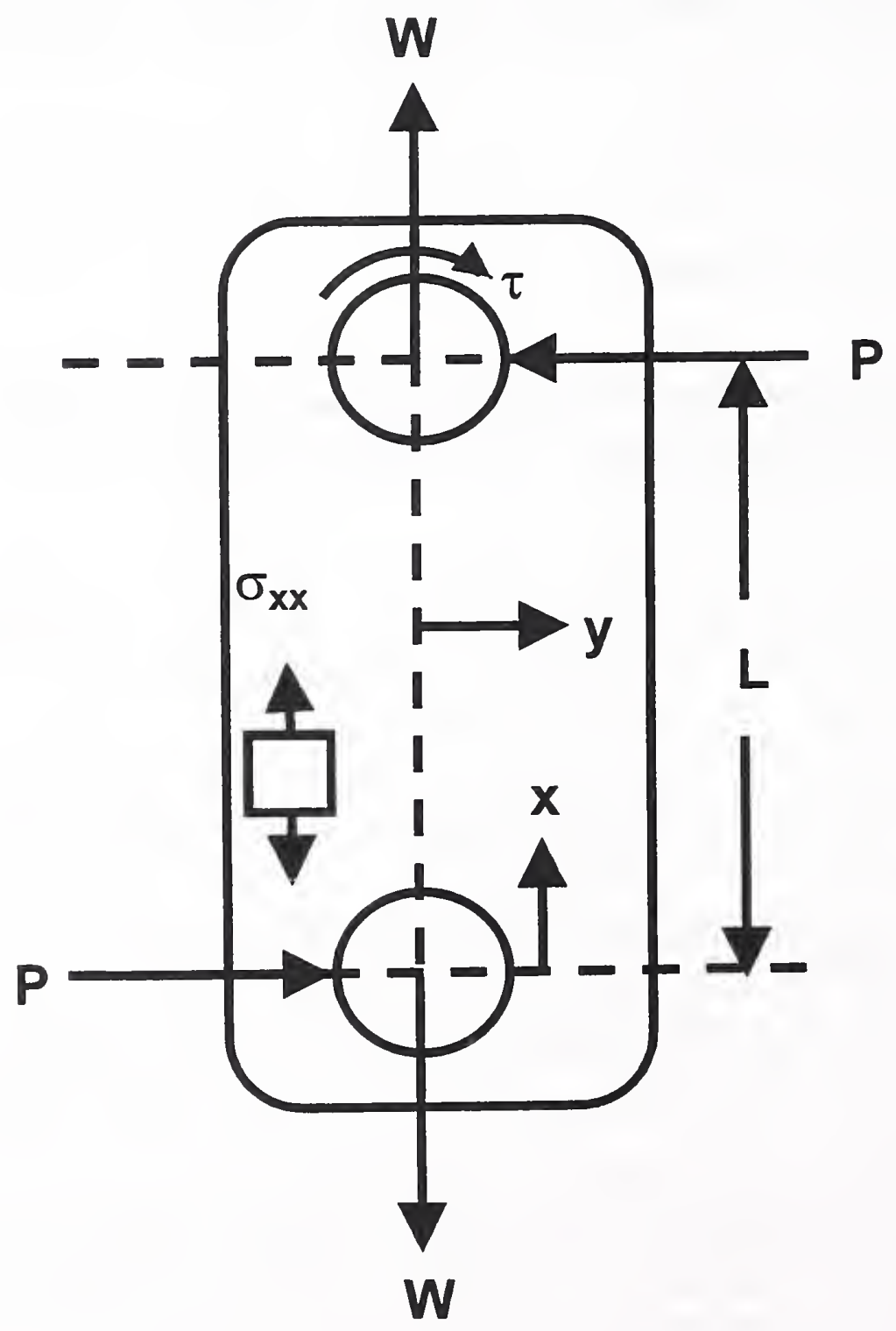

Figure 2. Forces, moments, and stresses acting on pin and hanger connection. Here only the top pin is locked. 
We approximate the pin shear stress $\sigma_{\theta_{z}}$ by the stress distribution in a cylinder loaded by torques acting at its ends. For this case, $\sigma_{\theta z}=\tau \mathrm{r} / \mathrm{J}$ where $\mathrm{J}=$ polar moment of inertia. For a solid cylinder, $\mathrm{J}=\tau \mathrm{r}_{\mathrm{o}}^{4} / 2$, where $\mathrm{r}_{\mathrm{o}}=$ cylinder radius.

This analysis pertains only to lockup of the top pin; the other is assumed free. The case where top and bottom pins are locked up is considered in the Appendix.

\subsection{Acoustoelastic Relations}

Stress causes a change in the sound speed. The relation between stress and velocity change for rolled sections of cubic metals (steel, aluminum) has been developed by several authors and is reviewed in Refs. 10 and 11 .

Here we use the acoustic birefringence method, which requires measurements of velocities of orthogonally polarized shear waves propagating through the material thickness. The normalized difference in velocity is called the acoustic birefringence B:

$$
\mathrm{B}=\left(\mathrm{V}_{\mathrm{f}}-\mathrm{V}_{\mathrm{s}}\right) / \mathrm{V}_{\mathrm{ave}},
$$

where $V_{f}=$ velocity of the fast wave, $V_{s}=$ velocity of the slow wave, $V_{\text {ave }}=$ average velocity. For the hanger the relation between $\mathrm{B}$ and stress is given by $[12,13]$

$$
\mathrm{B}=\left\{\left[\mathrm{B}_{\mathrm{o}}+\mathrm{m}\left(\sigma_{\mathrm{yy}}-\sigma_{\mathrm{xx}}\right)\right]^{2}+\left(2 \mathrm{~m} \sigma_{\mathrm{xy}}\right)^{2}\right\}^{1 / 2} .
$$

Here the stresses are referenced to a coordinate system parallel and perpendicular to the hanger rolling direction. Typically hangers are made of A-36 steel, which has a stress-acoustic constant $\mathrm{m}=0.92\left(10^{-5}\right) \mathrm{MPa}^{-1}$.

In the absence of stress the pure mode polarization directions will be along the rolling and transverse directions in the hangers. The shear stress $\sigma_{x y}$ will cause rotation of these directions through an angle $\varphi$ given by $[12,13]$ :

$$
\tan 2 \varphi=2 m \sigma_{x y} /\left[B_{o}+m\left(\sigma_{y y}-\sigma_{x x}\right)\right] .
$$

Using trigonometric identities we can combine eqs (6) and (7) to obtain

$$
\sigma_{x y}=B \sin 2 \varphi / 2 m
$$

and

$$
\sigma_{\mathrm{yy}}-\sigma_{\mathrm{xx}}=\left(\mathrm{B} \cos 2 \varphi-\mathrm{B}_{0}\right) / \mathrm{m} .
$$

Note that $\mathrm{B}_{0}$ does not appear in the first of these equations; there is no need to characterize material in the unstressed state when measuring $\sigma_{x y}$. 
Assume that one pin locks up. Then, away from the pin, $\sigma_{y y}=0 ; \sigma_{x x, b}$ and $\sigma_{x y}$ are given by eqns. (3) and (4). The bending stress $\sigma_{x x>b}$ varies linearly with $Y$, reaching a maximum at the outer edges and vanishing at the centerline. $\sigma_{x y}=0$ at the outer edges and varies parabolically, reaching a maximum at the centerline. Therefore, in the hanger, we have two possible measurement techniques: (1) measure B near the edges where $\sigma_{x y}=0 ;(2)$ measure B and $\varphi$ near the center line where $\sigma_{x x, b}=0$.

For the first case, $\varphi=0$ and eq (9) reduces to eq (1). Now $\sigma_{x x}=W / A+\sigma_{x x>b}$ so assuming $\mathrm{B}_{\mathrm{o}}=$ constant we have

$$
B^{\prime}-B^{r}=m\left(\sigma_{x x>b}{ }^{r}-\sigma_{x x>b}{ }^{1}\right) .
$$

The right side is nonzero since $\sigma_{x x, b}$ is antisymmetric about the centerline.

For the second case eq (7) reduces to

$$
\tan 2 \varphi=2 \mathrm{m \sigma}_{\mathrm{xy}} / \mathrm{B}_{\mathrm{o}},
$$

so $\varphi \neq 0$. Then we measure $\varphi$ and B on the centerline and determine $\sigma_{x y}$ from eq (8). For a good hanger, $\sigma_{x y}=0$; for a bad hanger, $\sigma_{x y} \neq 0$.

Each technique has uncertainty. The first is influenced by material inhomogeneity. In general $\mathrm{B}_{0}$ is not constant; there will be an average value of $\mathrm{B}_{0}$ and a standard deviation $\delta \mathrm{B}_{0}$. The standard deviation will cause errors in the evaluation of hanger stress. Hence for a good hanger we have the possibility of a false reject.

In the second technique we need to determine $\varphi$ accurately. We estimate that $\varphi$ can be determined within $\pm 5^{\circ}$ with our current measurement technique. An error propagation analysis leads to the conclusion that measurement of shear stress has more uncertainty; see Appendix.

This discussion applies only to the hangers. We could also measure velocities in the pin to characterize $\sigma_{\theta z}$. However there are potential difficulties with this due to pin geometry (see Appendix). Therefore we discarded the idea of ultrasonic measurements in pins as impractical.

\section{Experimental Facility}

\subsection{Pin and Hanger Simulator}

We designed an apparatus to simulate the stress state in a pin and hanger connection with one pin locked up. The basic components are shown in Figure 3. A large clamp was bolted to a stiff plate which was in turn secured to the base of a $1000 \mathrm{kN}$ 
(225 kip) mechanical testing machine by four cylindrical columns. The purpose of the columns is to position the hangers as close as possible to the machine crosshead. (A long piston displacement, coupled with any out-of-plane bending, could rupture the piston's hydraulic seals.)

A 12-tooth spline was inserted into the clamp. (This simulates the locked-up pin). The spline projected $51 \mathrm{~mm}$ ( 2 in) on both sides of the clamp. The two hangers were then mounted on the spline. A cylindrical pin was inserted through holes at the opposite ends of the hangers. The distance from the spline center to the pin center is $381 \mathrm{~mm}$ (15 in).

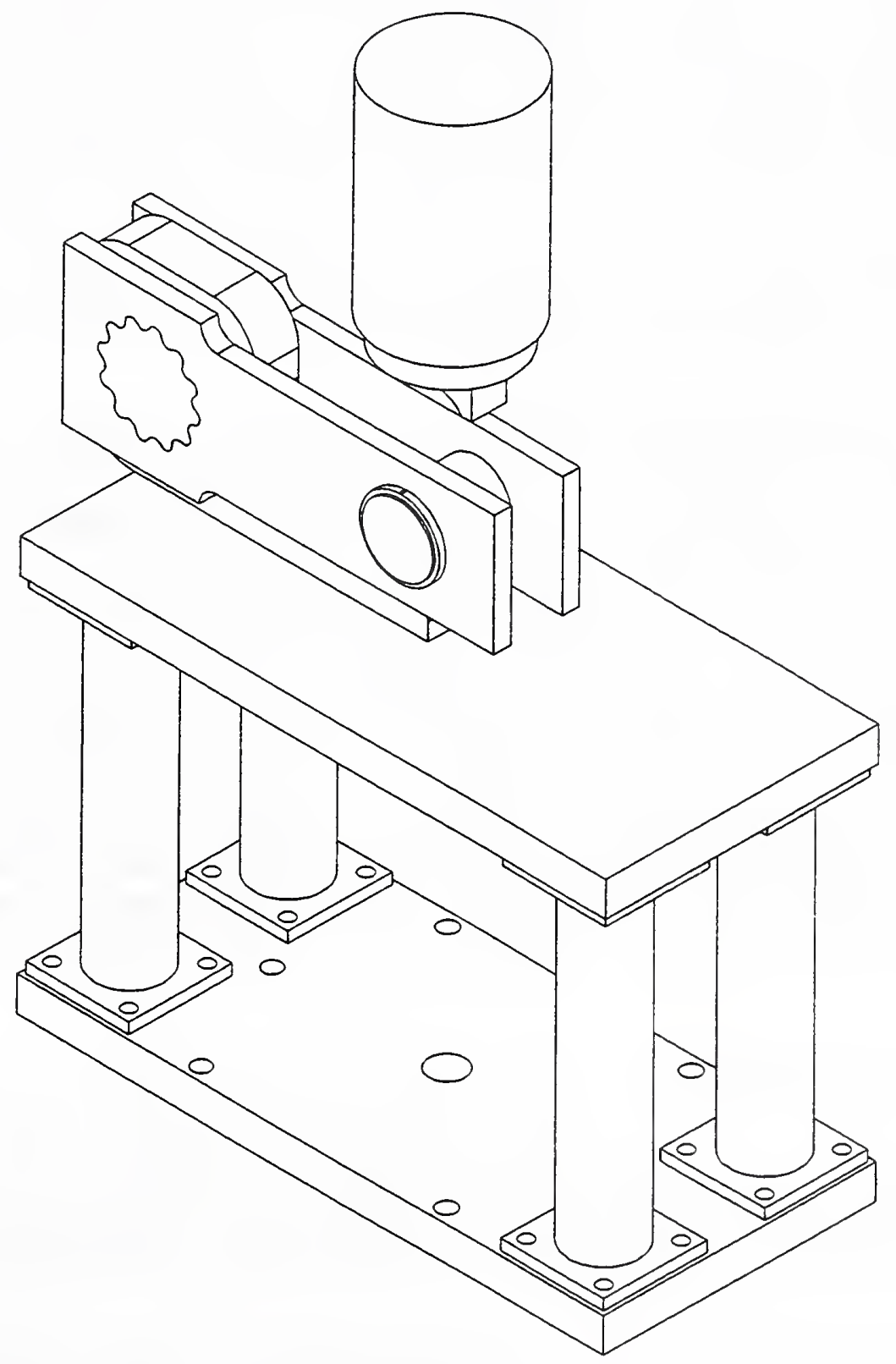

Figure 3. Apparatus for simulating locked-up pin and hanger connection. 
The apparatus is loaded by the piston of the mechanical testing machine. An adapter is bolted to the bottom of the piston. The adapter has a bearing surface, which presses down on the pin; the bearing surface has the same radius as the pin.

The hanger dimensions are based on blueprints obtained from the West Virginia Highway Department for the Osage Bridge in Monongalia County. In the test section of the hangers, the depth is $177.8 \mathrm{~mm}$ ( $7 \mathrm{in})$, and thickness is $25.4 \mathrm{~mm}$ ( 1 in). Except for the spline region we have a full-scale replica.

The key element in our apparatus is the spline, which prevents rotation at one end of the hangers. In designing the spline, we performed a simple optimization to maximize the safety factor; see Appendix. This is necessary since the spline teeth are subject to combined bending and bearing stresses. A simple stress analysis shows that the peak stress occurs at the base of the spline teeth. We found that the maximum safety factor occurs when the aspect ratio $l_{\mathrm{r}} h_{\mathrm{t}}$ is $\sqrt{3} / 3$; here $l_{t}=$ length of tooth, $h_{\mathrm{t}}=$ depth of tooth.

This aspect ratio was used as a starting point for design of the spline. After selecting radii at the base and tip of the spline (to minimize stress concentrations there), a finite element analysis was performed to identify critical regions.

The spline was made of a high-strength steel which has a yield stress of $450 \mathrm{MPa}$ (65 ksi). Since the hangers were of A-36 steel with yield stress of $252 \mathrm{MPa}$ (36 ksi), yielding will occur in hangers before yielding in the spline. Our finite element analysis showed that yielding would occur at the base of two of the teeth, for a load of $89 \mathrm{kN}$ ( 20 kip). (These teeth are located near the upper radius machined into the hangers.) Therefore the maximum load applied to the hangers was restricted to $44.5 \mathrm{kN}$ (10 kip).

Two strain gages were mounted on each hanger along a vertical line midway between the spline and the pin. One was placed $25.4 \mathrm{~mm}(1 \mathrm{in})$ from the top of the hanger, and the other $25.4 \mathrm{~mm}$ from the bottom of the hanger. The gages were placed on the inside of the hangers so that we could position transducers on the outside for ultrasonic measurements. This allows us to compare our ultrasonic measurement with strain gage results. All gages were oriented in the horizontal direction to measure the strain $\sigma_{\mathrm{xx}}$.

\subsection{Ultrasonic Equipment}

A block diagram of our ultrasonic system is shown in Figure 4. We performed birefringence measurements using a commercially available swept-frequency phasesensitive instrument. Details of operation are given in Ref. 14. Here we summarize features pertinent to our experiments.

In the instrument a synthesizer generates a CW signal at a frequency selected by the operator. The signal is input to a gated amplifier, which generates high power 


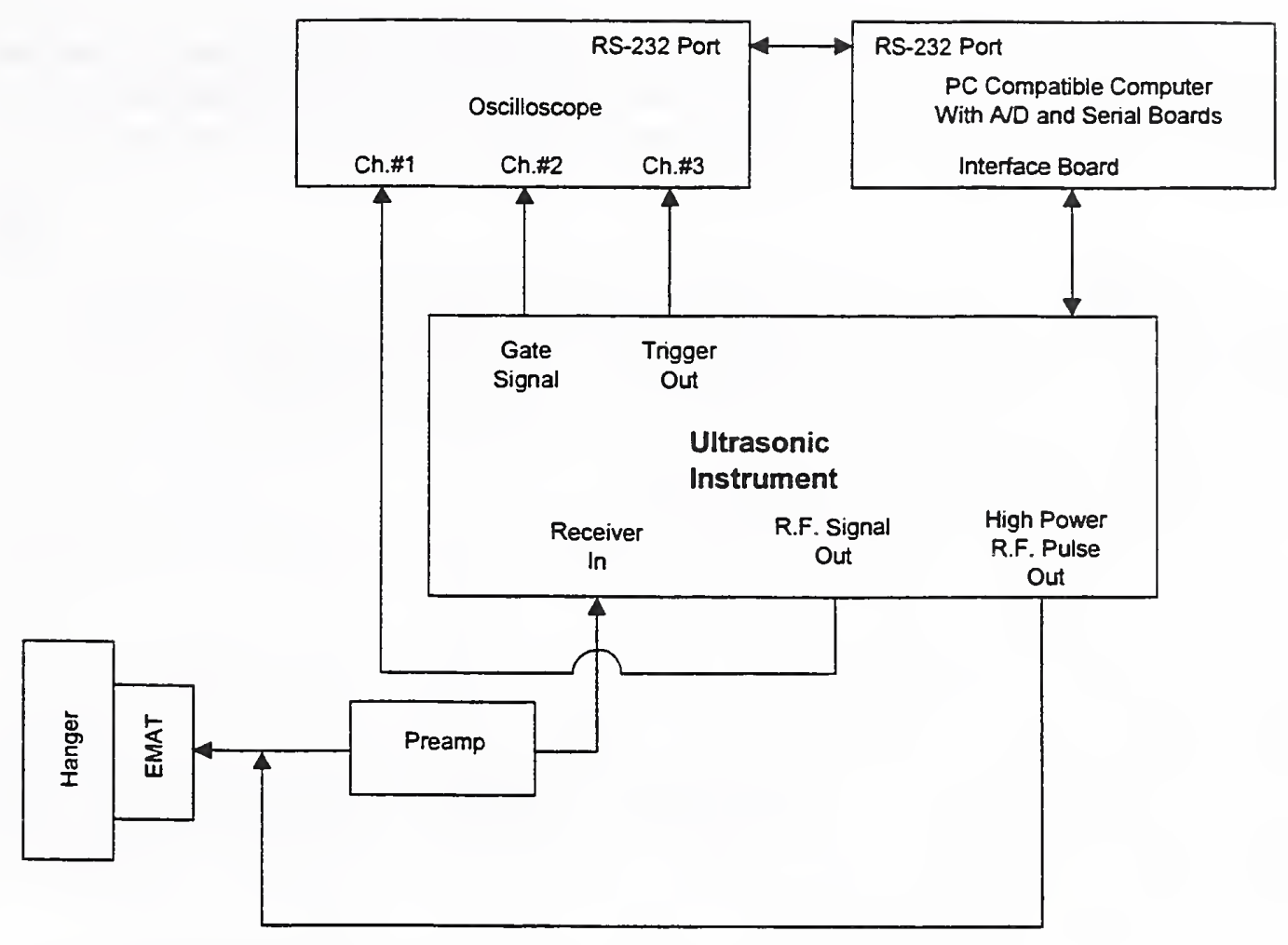

Figure 4. Block diagram of system for ultrasonic measurement of stress.

tonebursts. The tonebursts excite the transducer, which generates and receives waves in the specimen. The received signal is conditioned by a preamplifier and further amplified by the receiver section of the instrument.

The toneburst has the form $A \sin \omega t$, where $\omega=2 \pi f, f=$ frequency of toneburst. After propagation through the specimen and subsequent amplification we have received signals in the form of a series of echoes:

$$
S=\Sigma A_{n} \sin \left(\omega t+P_{n}\right) .
$$

Here $A_{n}=$ amplitude of the $n_{t h}$ echo, $P_{n}=$ phase in the $n_{t h}$ echo. For specimen thickness $d$ we have $P_{n}=2 \omega n d / V$, where $V=$ sound velocity.

The operator places an electronic gate over a selected echo. The gated signal is mixed with a signal of the form $\cos \omega t$ derived by shifting the $\mathrm{CW}$ signal from the synthesizer by $90^{\circ}$. This gives two signals: $1 / 2 A_{n}\left[\sin \left(2 \omega t+P_{n}\right)+\sin P_{n}\right]$. The frequencydoubled component is removed by low pass filtering leaving $1 / 2 A_{n} \sin P_{n}$. In a second channel the amplified echo is multiplied by $\sin \omega t$. Low pass filtering this gives a signal $1 / 2 A_{n} \cos P_{n}$. 
The signals $A_{n} \sin P_{n}$ and $A_{n} \cos P_{n}$ are sampled by an $A / D$ converter and the data are transmitted to the computer. In software the computer calculates the phase $P_{n}$;

$$
P_{n}=\tan ^{-1}\left\{A_{n} \sin P_{n} / A_{n} \cos P_{n}\right\} .
$$

Typically $P_{n}$ will be about 800 rad for our experiments. We can write $P_{n}=Q_{n}+$ $2 N \pi$ where $0<Q_{n}<2 \pi$. Software for calculating $P_{n}$ in eq (13) only obtains $Q_{n}$. In general we need supplementary information to obtain the missing $2 \mathrm{~N} \pi$.

We determine the birefringence from

$$
\mathrm{B}=\left(\mathrm{P}_{\mathrm{s}}-\mathrm{P}_{\mathrm{f}}\right) / \mathrm{P}_{\text {ave }}
$$

where $P_{f}, P_{s}$ are the phases of the fast and slow waves and $P_{\text {ave }}$ is the average phase. In our experiments the birefringence is so small that the $2 \mathrm{~N} \pi$ term is the same for both orientations; we obtain $\mathrm{P}_{\mathrm{f}}-\mathrm{P}_{\mathrm{s}}$ from a relative phase measurement. That is, we orient the transducer to generate a wave in fast direction and have the computer determine $P_{n}$ (from eq (13) at this orientation. We then repeat this process for the slow wave orientation and subtract the slow and fast phase data.

To determine $\mathrm{P}_{\text {ave }}$, we need to determine absolute phase (include the $2 \mathrm{~N} \pi$ term). We do this by performing a frequency sweep with our instrument, and measuring $\mathrm{P}$ versus $f$. For small increments $\Delta f$, the software now "tracks" the phase and adds the appropriate $2 \pi$ increments. The phase-slope $\Delta \mathrm{P} / \Delta \mathrm{f}$ is calculated by the computer. For a plane wave, $\Delta \mathrm{P} / \Delta \mathrm{f}=2 \pi \mathrm{t}_{\mathrm{n}}$, where $\mathrm{t}_{\mathrm{n}}=$ round-trip transit time of the $\mathrm{nth}$ echo. Hence we let $P_{\text {ave }}=(\Delta P / 2 \pi \Delta f) f_{o}$, where $f_{o}$ is the frequency of our toneburst when measuring $P_{s}-P_{f}$.

\subsection{Electromagnetic-Acoustic Transducer}

In our experiments we used an electromagnetic-acoustic transducer (EMAT) to generate and receive $\mathrm{SH}$-waves. EMATs are especially advantageous for our experiments because they can be easily attached to vertical steel surfaces; a permanent magnet is used as part of the EMAT transduction mechanism. Furthermore EMATs have good measurement reproducibility. For example: the EMAT is placed on the steel surface and the birefringence measured. The EMAT is then removed and replaced at the same location. Typically we find that the value of birefringence repeats to a few parts in $10^{5}$.

The basic EMAT consists of a coil and a magnet. When the coil is close to the surface of a conductor, it generates eddy currents in the material. These currents are (approximately) the mirror image of current in the coil. The eddy current density (current per unit area) is denoted as $\underline{\mathrm{J}}$. The magnet causes a magnetic induction $\underline{\mathrm{B}}$ in the 
specimen. There will be a Lorentz force $\underline{F}_{L}=\underline{J} \times \underline{B}$ exerted in the region of eddy currents. This force only exists near the surface, since the eddy currents decay with depth.

Furthermore, the current oscillates through the coil at the toneburst frequency. Therefore we have a dynamic shear stress distribution acting at the surface. Since this force is not in static equilibrium it sets up a linearly polarized shear wave propagating normal to the surface.

We used a custom-made EMAT in our experiments. The coil is wound in the shape of a square $25.4 \mathrm{~mm}$ on a side. Two magnets of square cross-section are connected to a shaft, which suspends them directly over the coil. The magnets are of opposite polarity so the south pole of one magnet and the north pole of the other is on the bottom. The shaft is rotated by the operator. With the magnets oriented as shown in Figure 5, the EMAT sets up an SH-wave with polarization perpendicular the direction of the wires. To obtain the SH-wave with the orthogonal polarization, the operator rotates the magnets $90^{\circ}$.

\section{Results}

\subsection{Description of Stress Measurement Scenarios}

We performed ultrasonic measurements simulating several scenarios: (1) continuous monitoring; (2) intermittent monitoring; (3) determination of connection status when the initial state is unknown.

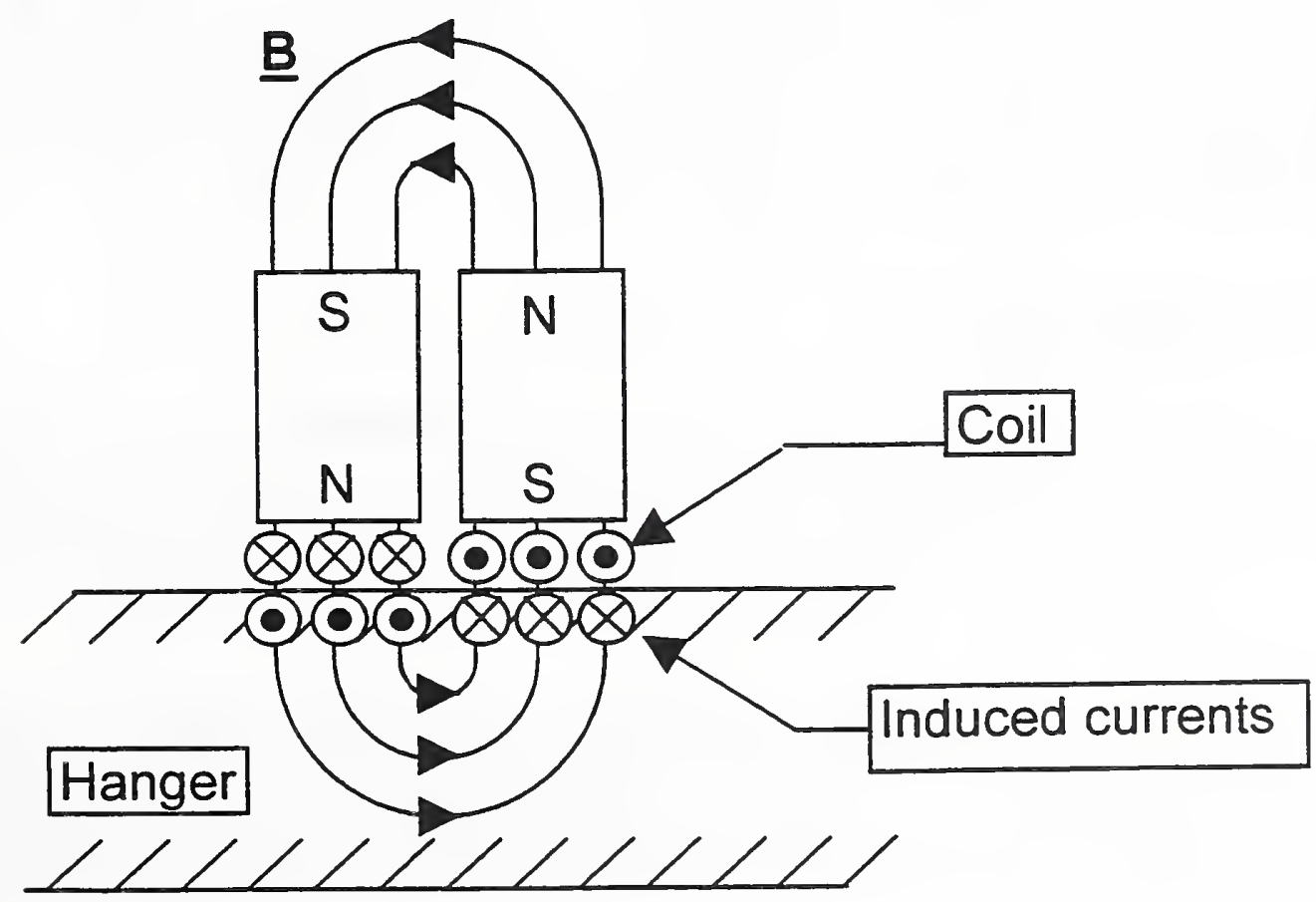

Figure 5. Schematic of EMAT. 
In the first case we assume that we have measured the birefringence at some initial state (for example when the hanger is installed) and continuously monitor changes (the EMAT remains in situ). In the second case we assume that baseline measurements are made at some initial state and the EMAT removed. Later we return to the bridge and measure changes from this state. In the last case we simulate making hanger inspections when corrosion products are visible but it is not known whether the hanger is actually locked up.

\subsection{Continuous Monitoring}

In these measurements the EMAT was left in situ and the birefringence measured for each load increment. This simulates leaving the EMAT on the bridge hanger for long term monitoring.

We changed the load in $4.4 \mathrm{kN}$ (1 kip) increments. For each load we measured the strains and birefringences at the four strain gage locations. For each location we calculated stress change $\Delta \sigma=\left(B-B_{0}\right) / m$ from birefringence data and the corresponding strain changes $\Delta \varepsilon^{\mathrm{u}}=\left(\mathrm{B}-\mathrm{B}_{\mathrm{o}}\right) / \mathrm{mE}$, withYoung's modulus $\mathrm{E}=210 \mathrm{GPa}\left(30(10)^{3} \mathrm{ksi}\right)$.

Figure 6 shows the comparison of strain changes $\Delta \varepsilon^{u}$ from ultrasonic data versus the strain gage data $\Delta \varepsilon$. Results for both hangers are shown. Strains at the upper locations become increasingly positive since this is the tensile side. Strains for the bottom locations become increasingly negative. If there was perfect agreement between ultrasonic and strain gage data, all data points would lie on the straight line in the figure. Good agreement between ultrasonic and strain gage data is evident. The rms error is only 5 microstrain, or about $1 \mathrm{MPa}(0.15 \mathrm{ksi})$. We attribute this error to the effect of random noise pickup by our EMAT on phase measurement.

\subsection{Intermittent Monitoring}

In this scenario we assume B was measured on the hangers at a known state; at some later time we return to measure changes from this state. To simulate this we first measured $\mathrm{B}_{\circ}$ at the measurement location, then removed the transducer and changed the load. Then we replaced the transducer and measured the birefringence at the new load. From $\Delta \varepsilon^{\mathrm{u}}=\left(\mathrm{B}-\mathrm{B}_{0}\right) / \mathrm{mE}$ we determined the strain change from the initial state.

We used a slightly different data reduction scheme for this scenario. For hanger 1 we subtracted the value of $\Delta \varepsilon^{u}$ at the lower location from that at the upper location; on hanger 2 we did the reverse. We followed the same procedure with the strain gage data. Hence in Figure 7, data from hanger 1 will fall in the third quadrant and data from hanger 2 in the first quadrant. 


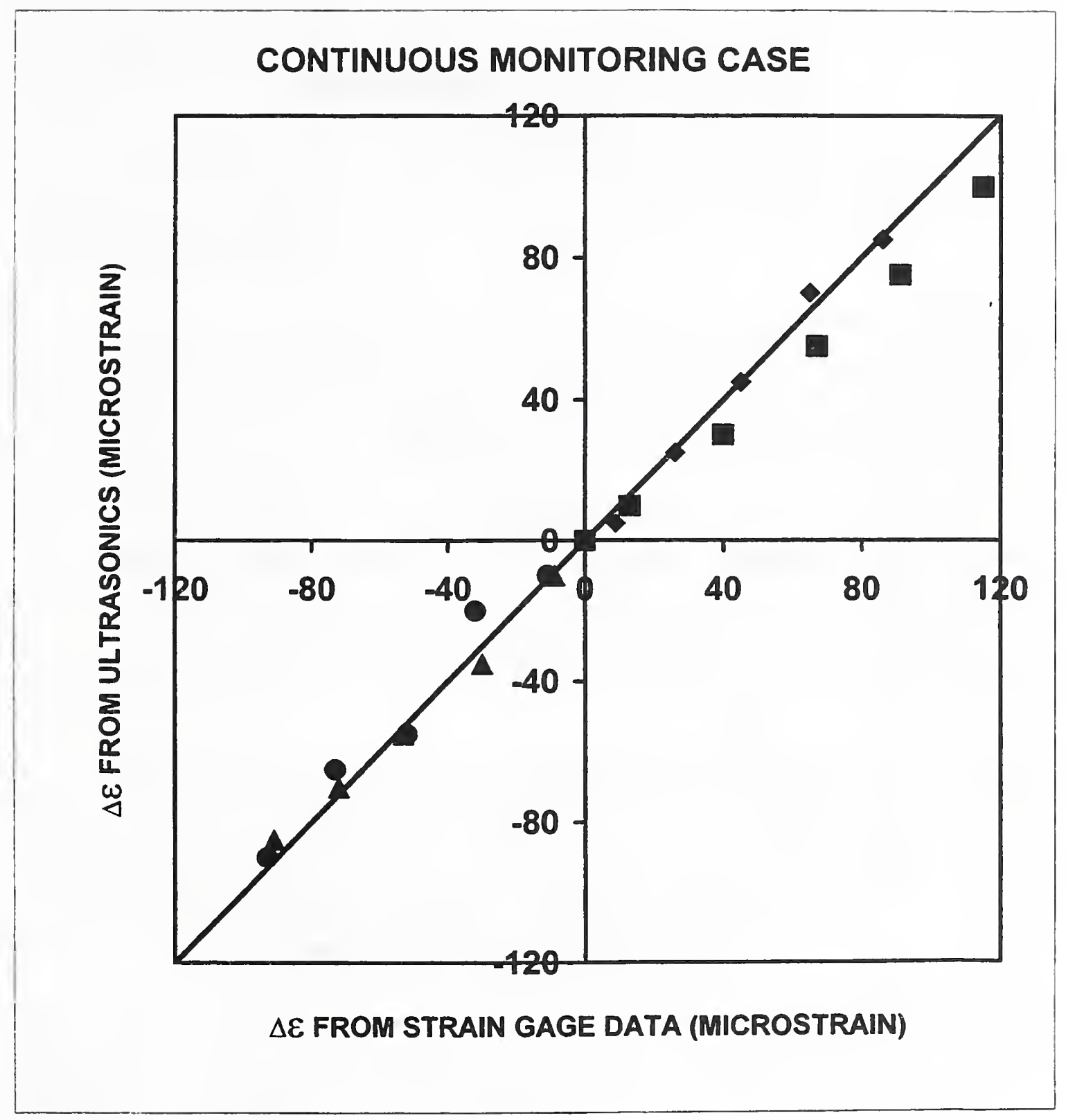

Figure 6. Comparison of strain changes $\Delta \varepsilon^{\mathrm{u}}$ from ultrasonic data with strain changes $\Delta \varepsilon$ from strain gages. Squares represent data taken at upper gage location on hanger 1 , triangles are data from lower gage on hanger 1. Diamonds represent data taken at upper gage location on hanger 2, circles are data from hanger lower gage on hanger 2 . The straight line indicates the perfect fit $\Delta \varepsilon^{\mathrm{u}}=\Delta \varepsilon$. 


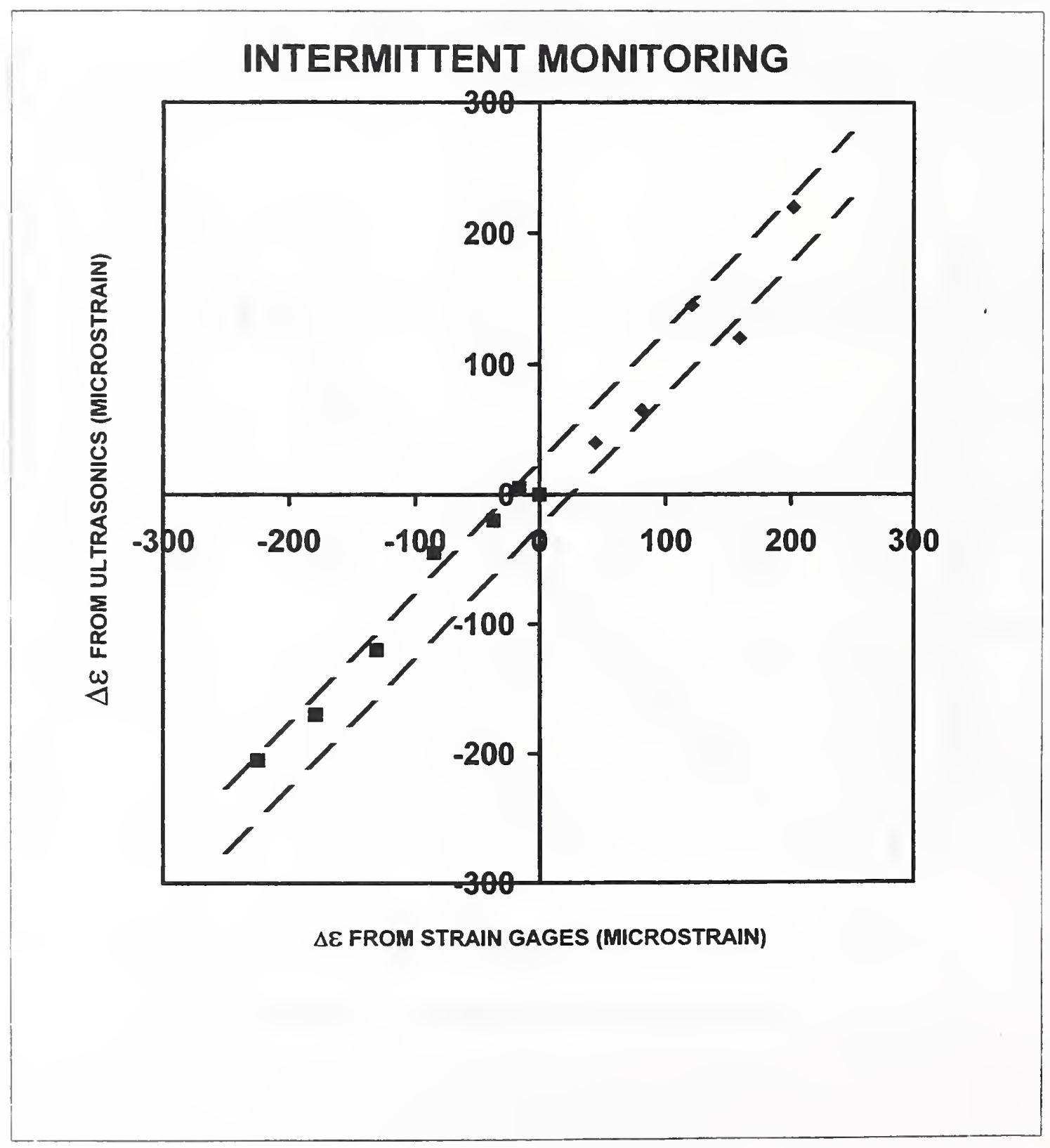

Figure 7. Comparison of $\Delta \varepsilon^{\mathrm{u}}$ with $\Delta \varepsilon$ for simulation of intermittent monitoring. Squares are data from hanger 1 , diamonds are data from hanger 2. Dashed lines indicate scatter bands equivalent to \pm 25 microstrain uncertainty. 
The data can be fit well with straight lines. For hanger 1 data we have: $\Delta \varepsilon^{\mathrm{u}}=16$ $+0.99 \Delta \varepsilon$ microstrain units $\left(16 \times 10^{-6}+0.99 \times 10^{-6} \Delta \varepsilon\right)$; for hanger $2, \Delta \varepsilon^{u}=-5+1.02 \Delta \varepsilon$ microstrain units $\left(-5 \times 10^{-6}+1.02 \times 10^{-6} \Delta \varepsilon\right)$. The rms error is about 25 microstrain; this is indicated by the dashed lines in the figure. In terms of stress we have errors of less than $5 \mathrm{MPa}(0.7 \mathrm{ksi})$ for this method.

These uncertainties are larger than those associated with the continuous monitoring case. We attribute the increased measurement errors to the fact that the birefringence measurements do not exactly repeat when the EMAT is removed and then replaced at the same location.

We compared our results (where an EMAT was used) with the results of Ref. 9 (where a piezoelectric transducer was used). From the ultrasonic and strain gage data in Ref. 9, we calculated an rms error of \pm 80 microstrain ( $\pm 16 \mathrm{MPa}$ ) for the piezoelectric transducer measurements. Presumably the EMAT results gave less uncertainty by eliminating the need for an acoustic couplant (which can introduce errors due to variation in acoustic pathlength).

\subsection{Measurement of Hanger Stress with No A Priori Information}

The most likely application of our method is to characterize hangers where corrosion is visible but it is not known whether lockup has occurred. Here the initial state of stress is unknown.

To simulate this case, we measured the birefringence at the upper and lower strain gage locations, over a range of loads. The EMAT was removed after each birefringence measurement, the load changed, and EMAT replaced for the next birefringence measurement at the new load, etc. We used the same data reduction scheme employed in the "Intermittent Monitoring" scenario. The results are shown in Fig. 8.

Data from hanger 1 can be fitted by $\Delta \varepsilon^{\mathrm{u}}=39+1.01 \Delta \varepsilon$, microstrain units $(39 \times$ $10^{-6}+1.01 \times 10^{-6} \Delta \varepsilon$ ). For hanger 2, the fit is $\Delta \varepsilon^{u}=-62+1.02 \Delta \varepsilon$ microstrain units $\left(-62 \times 10^{-6}+1.02 \times 10^{-6} \Delta \varepsilon\right)$. The rms error is about 55 microstrain, indicated by the dashed lines in the figure. The corresponding stress uncertainty is $11 \mathrm{MPa}$ (1.6 ksi).

The fact that the slopes in Figure 8 are approximately 1 indicates the correct trend in measurement. We claim that the nonzero intercepts are due to variability in $\mathrm{B}_{0}$. This variability is also the major cause of the rms error of 55 microstrain.

To prove this, we measured $B_{0}$ at 10 locations on an unloaded hanger. The standard deviation $\delta \mathrm{B}_{\mathrm{o}}=1.1\left(10^{-4}\right)$. Dividing this by the acoustoelastic constant $\mathrm{m}=0.92$ $\mathrm{MPa}^{-1}$ gives an equivalent stress error of about $13 \mathrm{MPa}(1.9 \mathrm{ksi})$. This is in agreement with the rms error corresponding to the data in Figure 8. 


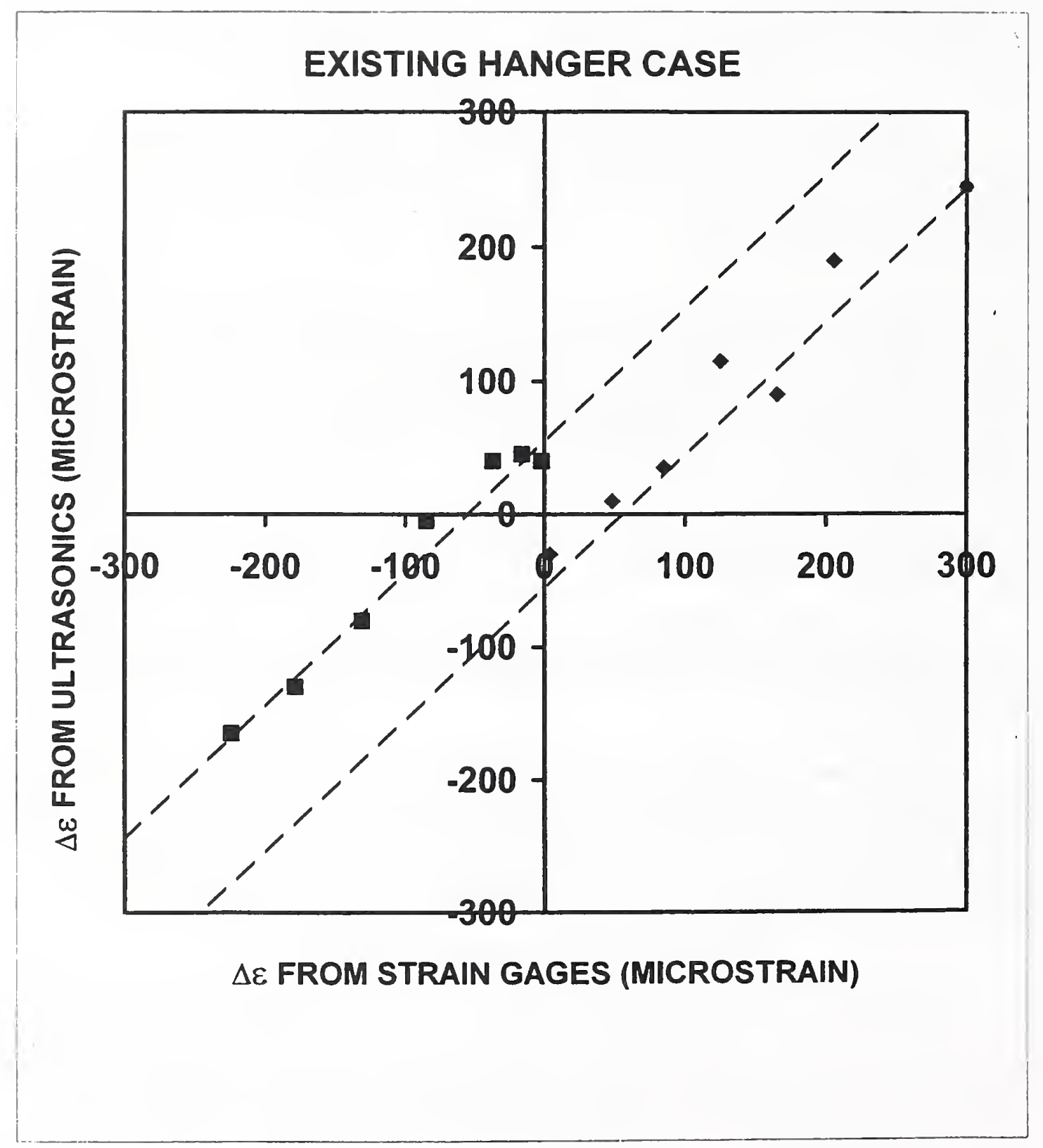

Figure 8. Comparison of $\Delta \varepsilon^{u}$ with $\Delta \varepsilon$ for case of no a priori information. Squares are data from hanger 1, diamonds are data from hanger 2. Dashed lines indicate scatter bands equivalent to \pm 55 microstrain uncertainty. 


\subsection{Effect of Measurement Uncertainties}

Suppose that our birefringence measurement technique were to be applied in the field, to characterize the status of pin and hanger connections. The laboratory measurements described above give different stress uncertainties, $\delta \sigma_{x x}$. From eq (3), there will be a corresponding uncertainty $\delta \mathrm{P} \cong 2 \mathrm{I}\left(\delta \sigma_{x x}\right) / \mathrm{Lh}$ in determination of the horizontal force $\mathrm{P}$.

For a good connection, $\mathrm{P}$ will be 0 . Because of measurement uncertainty, we have the possibility of a false reject (erroneously identifying a good connection as bad). Since $P$ is caused by thermal expansion, we have $P=\kappa \Delta T$, where $\kappa$ depends on bridge geometry; $\Delta \mathrm{T}$ is the difference between temperature at time of measurement and at time of lockup. If $\Delta \mathrm{T}$ and $\mathrm{K}$ can be estimated, measurements in the field should be done when

$$
\Delta \mathrm{T}>\left(2 \mathrm{I} \delta \sigma_{\mathrm{xx}}\right) /(\mathrm{Lh} \kappa)
$$

To determine $\kappa$ generally requires a finite-element analysis. For example, the result of lockup in connections in a truss bridge over the New River in Radford, Virginia has been calculated [15]. (Here the connections, or "links" are actually $6.08 \mathrm{~m}(22 \mathrm{ft})$ long I-beams with $228.6 \mathrm{~mm}\left(9\right.$ in) diameter pins.) For this structure, $\kappa=0.82 \mathrm{kN} /{ }^{\circ} \mathrm{C}(1$ kip/ ${ }^{\circ}$ F).

Using this value of $\kappa$, along with values of $\mathrm{I}, \mathrm{L}$, and $\mathrm{h}$ from the bridge blueprints, we find that $\Delta \mathrm{T}>0.4^{\circ} \mathrm{C}, 1.9^{\circ} \mathrm{C}$, and $4.4^{\circ} \mathrm{C}$. $\left(0.75^{\circ} \mathrm{F} ., 3.5^{\circ} \mathrm{F}\right.$, and $8{ }^{\circ} \mathrm{F}$.), respectively for scenarios (1), (2), and (3). (Here we assume that we would have the same error source in the field and laboratory measurements.)

With the minimum $\Delta \mathrm{T}$ estimated, we could then predict the required temperature at which the field test should be done. This assumes that the lockup temperature $T_{1}$ has been estimated.

If it is not possible to estimate $T_{1}$ then the measurements could be done when the bridge is at two different temperatures $T_{m 1}$ and $T_{m 2}$. To avoid the possibility of a false reject, we require that

$$
\left|\mathrm{T}_{\mathrm{m} 1}-\mathrm{T}_{\mathrm{m} 2}\right|>\left(2 \sqrt{2} \mathrm{I} \delta \sigma_{\mathrm{xx}}\right) /(\mathrm{Lh} \kappa) .
$$

Note the additional $\sqrt{2}$ factor in eq (16); it appears because of the addition of random errors.

Making birefringence measurement at two different temperatures is similar to the case of intermittent monitoring, so $\delta \sigma_{\mathrm{xx}}$ is due primarily to scatter in reproducing 
birefringence measurements when the EMAT is removed and then replaced at the same location.

\section{Conclusions}

We have designed and constructed a device to simulate the stress state in a locked-up pin and hanger connection. Our device simulates the case that one pin is locked up.

The key element in this device is a 12-tooth spline, which prevents rotation of the two hangers. In designing the spline we first performed a simple optimization to determine the aspect ratio (length/depth) of the teeth. Then a finite element analysis was performed to identify any localized regions of high stress where plastic deformation might occur. We found two such areas: at the base of two hanger teeth nearest the upper radius of the hangers. Theoretically these locations will yield when a load of $89 \mathrm{kN}(20$ kip) is applied by the testing machine.

Birefringence measurements were made using an EMAT, which was easily attached to vertical hanger surfaces. This is because the EMAT uses a permanent magnet as part of its transduction mechanism. In our laboratory experiments we simulated three measurement scenarios: (1) in-situ monitoring; (2) intermittent monitoring; (3) characterization of connection status with no a priori information.

For the in-situ monitoring simulation, the strains determined from birefringence measurements and from strain gage readings agreed to within about 5 microstrain. Here the dominant uncertainty in the ultrasonic measurements is noise pickup by the EMAT.

For simulation of intermittent monitoring, we measured $\mathrm{B}_{0}$ at each measurement location. Then we removed the transducer, changed the load, replaced the transducer, and measured change $\mathrm{B}-\mathrm{B}_{\mathrm{o}}$ at each location. Hence the major error source is in repeatability of measurement of $\mathrm{B}$. We found the rms error for this case was 25 microstrain, corresponding to a stress uncertainty of $5 \mathrm{MPa}(0.7 \mathrm{ksi})$.

In the third measurement scenario we assume no a priori information. We measured $B$ at opposite sides of the hanger, at the same distance from the load. If the connection is locked up, then $\mathrm{B}^{1}-\mathrm{B}^{r}$ is nonzero. For this case we found that changes in strain $\Delta \varepsilon^{u}$ from our ultrasonic measurements were related to corresponding strain gage data by: $\Delta \varepsilon^{u}=\mathrm{a}+\mathrm{b} \Delta \varepsilon$. The fact that the slope was almost equal to 1 for both hangers indicated a correct trend of $\Delta \varepsilon^{u}$. The nonzero intercept indicated an offset due primarily to $\mathrm{B}_{0}$. The rms error was 55 microstrain corresponding to a stress uncertainty of $11 \mathrm{MPa}$ (1.6 ksi).

Our measurements have demonstrated proof-of-concept of ultrasonic monitoring of pin and hanger connections. The technique is meant to detect hanger distress before 
cracking. Therefore we envision it as complementary to imaging techniques designed to detect existing cracks in pins.

We are grateful to G.A. Alers for the design of the EMAT used in our experiments. T.N. Nguyen constructed the EMAT. We also acknowledge the assistance of J.D. McColskey, R.L. Santoyo, and J. Boyd in the design and assembly of the pin and hanger simulation facility.

\section{References}

1. El-Khoury, A., Washer, G., Weigel, T.A., Finite element modeling of a pinhanger connection, Structural Materials Technology: A NDT Conference, San Diego, CA, Feb. 20-23, 1996, p. 284, Technomic, Lancaster, PA.

2. Komsky, J.N., Achenbach, J.D., A computerized imaging system for ultrasonic inspection of steel bridge structures, ibid, p. 40.

3. Schramm, R.E., Szelacek, J., Clark, A.V. Ultrasonic measurement of residual stress in the rims of inductively heated railroad wheels, Mat. Eval., 54(8):929, Aug. 1996.

4. Schramm, R.E., Szelacek, J., Clark, A.V., Dynamometer-induced residual stress in railroad wheels, ultrasonic and saw cut measurements, NISTIR 5043, Natl. Inst. Stand. Technol.; March 1995.

5. Fukuoka, H., Toda, H., Hirakawa, K., Sakamoto, H., Toya, Y. Acoustoelastic measurements of residual stresses in the rim of railroad wheels, Wave Propagation in Inhomogeneous Media and Ultrasonic Nondestructive Evaluation, Vol. 6, G.C. Johnson, ed., (Am. Soc. Mech. Eng., NY, 1984), p. 185.

6. Bartosiewicz, A., Brokowski, A., Deputat, J., Mizerski, K., Szelacek, J., Miniature ultrasonic stress gauge for in-service inspection of thermally damaged wheels, Proceedings, Eleventh Intentional Wheelset Congress, Vol. 1, Paris, June 1995, p. 241.

7. Schneider, E., Hintze, H., Dalichow, M., Ultrasonic techniques for evaluation of stress states in railroad wheels and rails, World Congress on Railway Research, June 17-19, 1996, Colorado Springs, CO, p. 425.

8. Lozev, M.G., Clark, A.V., Fuchs, P.A., Application of electromagnetic-acoustic transducers for nondestructive evaluation of stress in steel bridge structures, Virginia Trans. Res. Council, 530 Edgemont Road, Charlottesville, VA, April, 1996. 
9. $\quad$ King, R.R., Smith, V.D., Residual stress measurements in structural steels, Rep. No. 15-4660, Jan. 1978, Fed. Highway Admin., USDoT, Washington, DC 20590.

10. Pao, Y.H., Sachse, W., Fukuoka, H., Acoustoelasticity and Ultrasonic Measurement of Residual Stress, Physical Acoustics, Vol. XVII, p 61, Academic Press, New York, 1984.

11. Thompson, R.B., Lu, W.Y., Clark, A.V., Handbook of measurement of residual stresses, Ch. 7, Soc. for Exp. Mech., Fairmont Press, Lilburn, GA, 1996.

12. Okada, K., Stress-acoustic relations for stress measurements by ultrasonic techniques, J. Acoust. Soc. Jpn: (E), 1(3):193; 1980.

13. Iwashimizu, Y., Kubomura, K., Stress-induced rotation of polarization directions in slightly anisotropic materials, Int. J. Solids Structures, 9:99; 1973.

14. Fortunko, C.M., Peterson, G.L., Chick, B.B., Renken, M.L, Preis, A.L., Absolute measurements of elastic-wave phase and group velocities in lossy materials, Rev. Sci. Instrum., 63(6):3477; 1992.

15. 1994 Inspection Report, Route 11 (Memorial Bridge) over New R. Structure No. 060-1903, prep. for Virginia Dept. Trans., Salem District, Salem, VA 24153 by Hayes, Seay, Mattern \& Mattern Inc., Roanoke, VA 24016, June 1995.

16. Okada, K., Acoustoelastic Determination of Stress in Slightly Orthotropic Materials, Exp. Mech., 21(12):461; 1981. 


\section{APPENDIX}

\section{The Case of Both Pins Locked Up}

If both top and bottom pins are locked up, then there will be a torque $\tau=\mathrm{PL} / 2$ acting on each. The bending moment $M$ will now vary as $M=\tau(1-X / 2 L)$. Since $M$ vanishes at midsection, $\sigma_{\mathrm{xx}, \mathrm{b}}$ also vanishes there. In this case it appears best to measure $\sigma_{\mathrm{xx}, \mathrm{b}}$ at about one-quarter of the distance between pins. In the vicinity of the pins, the stress varies rapidly, and small errors in positioning of the transducer could lead to erroneous results in determining $\mathrm{B}^{1}-\mathrm{B}^{\mathrm{r}}$.

\section{Disadvantages of Measurement of Torsional and Shear Stresses}

Here we discuss the disadvantages of characterization of pin and hanger status by measurement of torsional stress $\sigma_{\theta z}$ in the pin, and shear stress $\sigma_{\mathrm{xy}}$ in the hanger.

To measure $\sigma_{\theta z}$ requires propagation of SH-waves through the pin. Since $\sigma_{\theta z}=$ $\tau \mathrm{r} / \mathrm{J}$ (increases radially from the pin center), the birefringence must be measured with the transducer positioned near the outer radius. However, most pins are long and slender, so sidewall effects will add phase artifacts to the measurements.

Furthermore, most pins are turned down at the ends, and threads are cut for the nuts which hold the hangers in place. This creates a "shoulder" that can also add artifacts due to diffraction. We require a method that is easy for relatively unskilled operators to use in the field. Therefore we think that birefringence measurements in the pins are not practical.

The shear stress $\sigma_{\mathrm{xy}}$ can be measured at or near the centerline of the hanger. This requires determination of the rotation $\varphi$ of the pure-mode polarization directions. Rearranging eq (8) gives

$$
\sigma_{x y}=(B \sin 2 \varphi) / 2 \mathrm{~m} .
$$

Now consider propagation of errors in this method. We have found that errors in $\varphi$ are usually larger than errors in B, so

$$
\delta \sigma_{\mathrm{xy}}=(\mathrm{B}(\delta \sigma) \cos 2 \varphi) / \mathrm{m},
$$

where $\delta \sigma_{x y}$ and $\delta \varphi$ are errors in $\sigma_{x y}$ and $\varphi$, respectively.

To estimate $\delta \sigma_{\mathrm{xy}}$ requires an estimate of $\delta \varphi$. At present two methods have been used to determine $\varphi$. In the first the operator rotates the transducer and observes the echo patterns on an oscilloscope. Any echo having $P_{s}-P_{f}$ equal to an odd multiple of $\pi$ will be 
extinguished when the transducer is oriented halfway between the slow and fast directions [16]. Unfortunately this method will not work for our case since the birefringence in our specimen is so small that no echoes were extinguished.

The second method also requires rotation and observation of the echoes. Now the operator determines when a maximum is reached; the transducer is then oriented along a pure-mode polarization direction. In our experience, applying this method with an EMAT gives an uncertainty in $\varphi$ of about $5^{\circ}$ (about $0.1 \mathrm{rad}$ ). Therefore we use $\delta \varphi=0.1$ in eq (24).

In general $\varphi$ will be small $(\cos 2 \varphi \cong 1)$. For our specimen, a typical birefringence $B$ is about $10^{-3}$. Using these values, along with $\mathrm{m}=0.9\left(10^{-5}\right) \mathrm{MPa}^{-1}$, we have from eq (24) $\delta \sigma_{x y} \cong \pm 10 \mathrm{MPa}$.

$\sigma_{\mathrm{xy}}$ is related to the force $\mathrm{P}$ which resists thermal expansion. At the hanger centerline $\sigma_{x y}=\mathrm{Ph}^{2} / 8 \mathrm{I}$. Therefore we have an uncertainty $\mathrm{P}_{\mathrm{sh}}=8 \mathrm{I}\left(\delta \sigma_{\mathrm{xy}}\right) / \mathrm{h}^{2}$ in determining $\mathrm{P}$; the subscript "sh" here denotes uncertainty associated with the shear stress measurement method.

We claim that measurement of $\sigma_{x x}$ will give less error in $\mathrm{P}$ than will measurement of $\sigma_{x y}$. The bending stress $\sigma_{x x, b}$ at midsection is related to P by $\sigma_{x x, b}=$ PLY/2I. We measure $B$ at locations on opposite sides of the hanger (where $Y \cong \pm h / 2$ ) and take the difference $\Delta B$ :

$$
\Delta \mathrm{B}=m\left(\sigma_{x x, b}^{r}-\sigma_{x x, b}^{l}\right)+\left(B_{o}^{l}-B_{o}^{r}\right)
$$

The largest uncertainty is due to variations in texture; in general, we find that $\mathrm{B}_{0}{ }^{\prime}$ is not equal to $\mathrm{B}_{0}{ }^{\mathrm{r}}$. Variation in texture can be characterized by the standard deviation $\delta \mathrm{B}_{0}$ in $B_{0}$. We measured $B_{0}$ both in our hangers (25 mm thick) and in two $12.7 \mathrm{~mm}$ thick A36 plates; for these materials we found $\delta B_{0}=0.15\left(10^{-4}\right)$.

For an uncertainty $\delta \mathrm{B}_{0}$ we have stress uncertainty $\delta \sigma_{\mathrm{xx}}=\delta \mathrm{B}_{\mathrm{o}} / \mathrm{m}$ or $\pm 15 \mathrm{MPa}$. This gives a corresponding uncertainty $\delta \mathrm{P}_{\mathrm{B}} \cong(4 \mathrm{I} / \mathrm{hL}) \delta \sigma_{\mathrm{xx}}$ in determining the reaction force $\mathrm{P}$.

Consider the ratio

$$
\delta \mathrm{P}_{\mathrm{sh}} \delta \mathrm{P}_{\mathrm{B}} \cong 2\left(\delta \sigma_{\mathrm{xy}} / \delta \sigma_{\mathrm{xx}}\right)(\mathrm{L} / \mathrm{h})
$$

Using the values of $\delta \sigma_{x y}, \delta \sigma_{x x}$ obtained above and our hanger dimensions $\mathrm{L}=381$ $\mathrm{mm}$ (15 in), $\mathrm{h}=177.8 \mathrm{~mm}$ ( $7 \mathrm{in}$ ), we find that the ratio is about 2.6. For hangers which are longer and/or more slender than those used here, the method of measurement of $\sigma_{x x}$ becomes even more favorable. 


\section{Design of Spline}

The critical element in our pin and hanger simulation facility is a spline which mimics the lockup due to corrosion. We chose the spline configuration because welding hangers to a pin would generate a complicated residual stress state, and using keys to connect the pin and hanger would lead to plastic deformation of the keys.

The spline must provide a torque $\tau=\mathrm{PL}$ where $\mathrm{P}$ is the load applied by the mechanical testing machine and $\mathrm{L}$ is the distance between the spline and pin centers. The torque is reacted by a bearing stress $\sigma_{\mathrm{n} n}$ acting over the area of contact between the spline and hanger teeth. Each tooth then acts like a small cantilever beam loaded on its surface. The critical point for yielding will be at the base of this cantilever.

Obviously, we want to avoid plastic deformation of the teeth if we wish to obtain reproducible results with our apparatus. A key design feature therefore is the aspect ratio (length/depth) of the teeth.

For simplicity, we ignore the effect of the taper of the teeth (the teeth have a wedge angle of $\theta$ ). It can easily be shown that this will introduce an error in the following analysis of $\cos \theta$; for small $\theta$ these errors can be neglected.

We first estimate the bearing stress due to contact between spline and hanger teeth. We assume for simplicity that $\sigma_{\mathrm{nn}}$ is constant for all teeth. From moment equilibrium $\sigma_{\mathrm{nn}}=\mathrm{PL} / \mathrm{Nbr}_{\mathrm{s}} \mathrm{l}_{\mathrm{t}}$, where $\mathrm{b}$ is the hanger thickness; $\mathrm{r}_{\mathrm{s}}$ is the radius of the spline; $l_{t}$ is length of the teeth. $N$ represents the number of teeth; $N=2 \pi r_{s} / S$, where $S=$ period of the teeth.

We assume that the hanger and spline teeth are approximately the same size so that $S=2 h_{t}$, where $h_{t}$ is tooth depth. Then we have

$$
\sigma_{\mathrm{nn}}=\left(\mathrm{PL} / \pi \beta \mathrm{br}_{\mathrm{s}}^{2}\right),
$$

where the tooth aspect ratio $\beta=1_{\mathfrak{r}} / h_{t}$

From beam theory the bending stress $\sigma_{\mathrm{bb}}$ in the hanger teeth will equal My/I. Here $M=-\sigma_{n n} b l_{t}^{2} / 2$ and $y$ is distance from the centerline of the tooth. For the small taper approximation, $\mathrm{I}=b \mathrm{~h}_{\mathrm{t}}{ }^{3} / 12 . \sigma_{\mathrm{bb}}$ is an extremum at $\mathrm{y}=\mathrm{h}_{\mathrm{t}} / 2$ where it equals $-3 \sigma_{\mathrm{nn}} \beta^{2}$.

We designed the teeth to have the maximum safety factor. To do this we used the yield criterion; since $\sigma_{\mathrm{nn}}$ and $\sigma_{\mathrm{bb}}$ are principal stresses at the critical point this becomes

$$
2 \sigma_{y s}=\sigma_{n n}^{2}\left(1+\left(3 \beta^{2}\right)^{2}+\left(1+3 \beta^{2}\right)^{2}\right) .
$$


The maximum safety factor occurs when the right side is a minimum; this requires $\beta=\sqrt{3} / 3$. If $\beta<\sqrt{3} / 3$ then $\sigma_{\mathrm{nn}}$ is greater than $\sigma_{\mathrm{bb}}$, and the tooth fails by crushing of the bearing surface. If $\beta>\sqrt{3} / 3$ failure occurs because of bending of the tooth at its base $\left(\sigma_{b b}\right.$ is greater than $\sigma_{n n}$ ).

We set $\beta=\sqrt{3} / 3$ in the yield criterion and use eq (21) for the bearing stress. This gives a relation between the bending moment PL, and spline and hanger geometry:

$$
\sigma_{y s} \geq 3 \mathrm{PL} /\left(\pi b_{s}^{2}\right) .
$$

In applying eq (23) we use the nominal yield stress of the hanger, since it is less than the yield stress of the spline.

We want to develop a maximum bending stress $\left|\sigma_{x x, b}\right|=69 \mathrm{MPa}(10 \mathrm{ksi})$ at the locations where the ultrasonic measurements are performed. Since the hanger dimensions are fixed, this requirement also fixes the value of PL in eq (23). Hence to avoid yielding, the spline radius must satisfy the inequality in eq (23). For our hanger dimensions, we find $r_{s}>53 \mathrm{~mm}(1.9 \mathrm{in})$. For an additional safety factor we made the actual spline radius equal to $70 \mathrm{~mm}(2.75 \mathrm{in})$.

The final step in the design of spline/hanger teeth was to perform a finite element analysis to identify any localized regions of high stress where yielding might initiate. (Recall that our analysis to this point assumed that the torque PL was uniformly reacted by all teeth. Obviously this is not the case.)

We found two regions of stress concentration: at the base of the two teeth nearest the upper radius machined into the hangers. (This radius can be seen in Fig. 3.) If a large enough load is applied to the hangers, eventually slip bands will form between the two teeth and this radius, with resulting plastic deformation. Our analysis showed that the stresses at the base of these two critical teeth remain below yield provided that we keep the piston load $\mathrm{P}$ below $89 \mathrm{kN}$ (20 kip). 

